\title{
OVULATION, FERTILITY AND PRENATAL MORTALITY IN HEIFERS TREATED WITH PMSG OR PORCINE FSH
}

\author{
D. B. LASTER \\ U.S. Department of Agriculture, Agricultural Research Service, \\ Animal Science Research Division, Meat Animal Research Center, \\ Clay Center, Nebraska 68933, U.S.A.
}

(Received 25th March 1972)

Summary. Ovulation rate, fertilization rate and prenatal mortality were studied in yearling beef heifers treated with PMSG or FSH and in non-treated controls. Oestrus was synchronized in $50 \%$ of the animals in each treatment with an oral progestagen. The gonadotrophin injections were given during the normal oestrous cycle or during the progestagen-administration period. All heifers were inseminated 6 to $10 \mathrm{hr}$ after observation of standing oestrus. Ovulation rate and percentage fertility were determined in approximately a third of the animals in each treatment group. The reproductive tracts of the remaining animals were examined 81 to 104 days after insemination for number and condition of fetuses, number of corpora lutea and condition of the uteri.

Ovulation and fertilization rates were $1.0 \pm 0.4$ and $100 \%$ for the controls, $1.6 \pm 1.0$ and $87.5 \%$ for the PMSG treatment and $4.4 \pm 4.9$ and $56.5 \%$ for the FSH treatment. Treatment with a gonadotrophin during progestagen administration resulted in higher ovulation rates than gonadotrophin treatment during the normal oestrous cycle, $36 \%$ higher in heifers given PMSG and $47 \%$ higher in those given FSH.

There was a negative relationship between ovulation and fertilization rates; therefore, the average number of fertilized ova/heifer increased as ovulation rate increased, but at a slower rate. Percentage fertility was not affected by the progestagen in the control and PMSG groups, but it was lower when FSH was given during progestagen treatment than when it was given during the normal oestrous cycle.

At 81 to 104 days after insemination, abortions had occurred in $20 \%$ of the animals treated with PMSG or FSH. There were no apparent differences in prenatal mortality between the PMSG- and FSH-treated animals.

\section{INTRODUGTION}

Limited multiple ovulation and multiple births can be induced in cattle by treatment with PMSG (Gordon, Williams \& Edwards, 1962; Schilling \& 
Holm, 1963; Laster, Turman, Stephens \& Renbarger, 1971; Turman, Laster, Renbarger \& Stephens, 1971) or FSH (Bellows, Anderson \& Short, 1969; Bellows \& Short, 1971; Vincent \& Mills, 1972).

Although promising results for inducing multiple births in cattle have been obtained, a lack of repeatability in ovarian response and birth rate from similar treatment regimens have deterred development of a procedure suitable for practical utilization. One problem is the variation in ovarian response among animals receiving the same exogenous hormone treatment. It has been shown that maintenance of a constant level of FSH in the systemic circulation of heifers during late pro-oestrus will not eliminate the variation in follicular stimulation among different animals (Laster, 1972). Some of the variation in the results of different studies has apparently been due to unknown differences in the biological potency of the gonadotrophin preparations used. Different commercial preparations of porcine FSH with the same labelled potency, assayed by the procedure of Steelman \& Pohley (1953) varied as much as $350 \%$ in FSH potency relative to NIH-FSH-S1 (L. L. Anderson, D. B. Laster \& R. M. Melampy, unpublished data).

Fertilization rate and prenatal mortality influence the percentage of multiple births resulting from induced multiple ovulation and both are apparently affected by ovulation rate (Gordon et al., 1962; Bellows \& Short, 1971). These two components of induced multiple births in cattle have not been well defined.

The purpose of this study was to determine ovulation and fertilization rates in heifers treated with PMSG or FSH during pro-oestrus or during suppression of oestrus with an oral progestagen, using treatment regimens similar to ones which have been successful in other studies, and to estimate prenatal mortality during the first trimester of gestation after treatment with PMSG or FSH.

\section{MATERIALS AND METHODS}

Yearling Hereford heifers, ranging in weight from 287 to $400 \mathrm{~kg}$, were randomly assigned to one of three treatments (Control, PMSG or FSH). Treatments and numbers of animals are shown in Table 1 . The heifers were checked twice daily for oestrus and all heifers were observed in standing oestrus before random assignment to the treatments. Ovarian activity was suppressed in approximately $50 \%$ of the heifers in each treatment by feeding 6 -chloro- $\Delta^{6}$-acetoxyprogesterone (CAP) for 16 days, $10 \mathrm{mg} /$ heifer/day for the first 14 days and $5 \mathrm{mg} /$ heifer/day for the last 2 days.

In the PMSG-non-synchronized group, the PMSG (Equinex) injections were given, subcutaneously, on Day 5 (1500 i.u.) and Day 17 (2000 i.u.) of the oestrous cycle, counting the day of oestrus as Day 0. The PMSG-synchronized heifers were injected subcutaneously with 1500 i.u. on Day 5 and 2000 i.u. on Day 16 of the CAP-treatment period.

In the FSH(Armour FSH-P, Lot No. K498159)-non-synchronized group, each heifer was injected intramuscularly twice daily for 5 days, with a total dosage of $12 \mathrm{mg}$ (NIH-FSH-S1 equiv.) porcine FSH. The injections were given on Days 13 to 17 of the oestrous cycle, counting day of oestrus as Day 0. In the FSH-synchronized group, FSH (12 mg) was injected intramuscularly 
twice daily on Days 12 to 16 of the CAP-treatment period. The total FSH dosage was given in saline solution in ten equal injections in both the FSH-nonsynchronized and synchronized treatments.

The PMSG- and FSH-treated heifers were inseminated at the first oestrus after the last gonadotrophin injection. Heifers in the synchronized control group were inseminated at the first oestrus after progestagen withdrawal. Inseminations were initiated in the non-synchronized controls at the beginning of the CAP-treatment period in the synchronized groups. All heifers were inseminated 6 to $10 \mathrm{hr}$ after observation of standing oestrus, using frozen semen obtained from commercial artificial insemination organizations.

The ovaries, oviducts and anterior portions of the uteri were removed through a paralumbar incision 60 to $72 \mathrm{hr}$ after insemination in approximately a third of the heifers from each treatment group (Table 1). Ova were recovered by flushing the oviducts and, if necessary, the uterine horns with a physiological

Table 1. Number of heifers and type of data obtained in each treatment group

\begin{tabular}{l|c|c|c}
\hline $\begin{array}{c}\text { Gonadotrophin treatment } \\
\text { and synchronization } \\
\text { of oestrus }\end{array}$ & $\begin{array}{c}\text { No. of } \\
\text { heifers }\end{array}$ & $\begin{array}{c}\text { No. of heifers } \\
\text { for which data } \\
\text { were obtained on } \\
\text { ovulation and } \\
\text { fertilization rates }\end{array}$ & $\begin{array}{c}\text { No. of heifers } \\
\text { with fetuses } \\
90 \text { days } \\
\text { post-insemination }\end{array}$ \\
\hline $\begin{array}{c}\text { Control } \\
\text { Non-synchronized }\end{array}$ & 21 & 8 & 13 \\
$\quad$ Synchronized & 20 & 7 & 13 \\
$\begin{array}{l}\text { PMSG } \\
\text { Non-synchronized }\end{array}$ & 25 & 8 & 17 \\
$\quad$ Synchronized & 22 & 7 & 15 \\
FSH & 22 & 8 & 14 \\
$\quad$ Non-synchronized & 24 & 8 & 16 \\
Synchronized & 134 & 46 & 88 \\
\hline Total & & & \\
\hline
\end{tabular}

saline solution. The ova were examined in hanging-drop preparations under phase-contrast microscopy, at $\times \mathbf{4 4 0}$ magnification, for cleavage, presence of sperm cells in the zona pellucida and evidence of morphological abnormalities (Hafez, 1962). Ova recovery rates were based on the number of corpora lutea. The number of fertilized ova per heifer was estimated for each treatment group by multiplying mean ovulation rate by percentage fertility. If it is assumed that the cleavage rates in the recovered and unrecovered ova were similar, this estimate allows usage of the ovulation and cleavage rate data from all the animals rather than only the data on those animals from which ova were recovered.

The reproductive tracts of the remaining heifers were obtained at necropsy 81 to 104 days after insemination. The number and condition of the fetuses, number of corpora lutea and condition of the uteri were determined. Heifers with uteri containing blood were classified as having aborted.

All heifers were fed a ration consisting of corn silage, wheat, grain sorghum 
and a protein supplement (soybean oil meal), fortified with minerals and vitamin $\mathrm{A}$. The ration was formulated to contain $65.6 \%$ total digestible nutrients and $10.4 \%$ crude protein during the initial phase of the experiment, and $73.4 \%$ total digestible nutrients and $11.0 \%$ crude protein during the last 90 days of the experiment.

The data were analysed by standard analysis of variance and $\chi^{2}$ procedures (Steel \& Torrie, 1960) and the variances were tested for heterogeneity by the procedure of Winer (1962).

\section{RESULTS}

The ovulation and fertilization data are shown in Table 2. Heifers treated with PMSG or FSH had higher $(P<0.01)$ ovulation rates than the controls. Ovulation rates were higher $(P<0.01)$ and more variable in heifers treated with FSH than in those treated with PMSG (4.4 \pm 4.9 compared to $1.6 \pm 1.0)$.

Treatment with PMSG or FSH during progestagen administration resulted in higher $(P<0.05)$ ovulation rates than treatment during the normal oestrous cycle. The mean ovulation rate was $36 \%$ higher in heifers given PMSG in combination with an oral progestagen than in those given PMSG during the normal oestrous cycle and $47 \%$ higher in heifers given FSH in combination with an oral progestagen, compared to treatment with FSH and no progestagen. The ranges in ovulation rates were 0 to 3 and 1 to 4 in the non-synchronizedand synchronized-PMSG treatments, respectively, and 1 to 7 and 1 to 19 in the non-synchronized- and synchronized-FSH treatments, respectively. One heifer in the synchronized control group and one in the non-synchronized-PMSG group failed to ovulate. One of the non-treated controls had two corpora lutea.

There was a negative relationship between ovulation and fertilization rates. The fertilization rate was $54.8 \%$ lower in the FSH-treated groups, which had an ovulation rate of $4 \cdot 4 \pm 4 \cdot 9$, than in the PMSG-treated groups, which had an ovulation rate of $1.6 \pm 1.0$ (Table 2). Treatment with progestagen did not influence the percentage fertility in the control or PMSG-treated groups. In heifers treated with FSH, the ovulation rate was $47 \%$ higher and the fertilization rate $88 \%$ lower when FSH was given in combination with a progestagen than when FSH was given alone.

The average number of fertilized ova/heifer increased as the ovulation rate increased, but at a slower rate (Table 2). The ovulation rate was $175 \%$ higher in heifers treated with FSH than in those treated with PMSG, while the mean number of fertilized ova was only $79 \%$ higher for heifers given FSH than for those given PMSG. Likewise, in the FSH-treated groups, the average number of fertilized ova was lower in the synchronized group than in the non-synchronized group $(2.3$ compared to 2.7$)$ because of the lower fertilization rate in the FSH-synchronized heifers $(42 \cdot 1$ compared to $79 \cdot 2 \%)$.

The percentage rate of ova recovery was not significantly affected by treatment and treatment had no effect on the number of ova found in the anterior portion of the uterine horns. Most $(96 \%)$ of the ova were recovered from the oviducts.

Two abnormal ova were observed; both were cleaved and were from a 


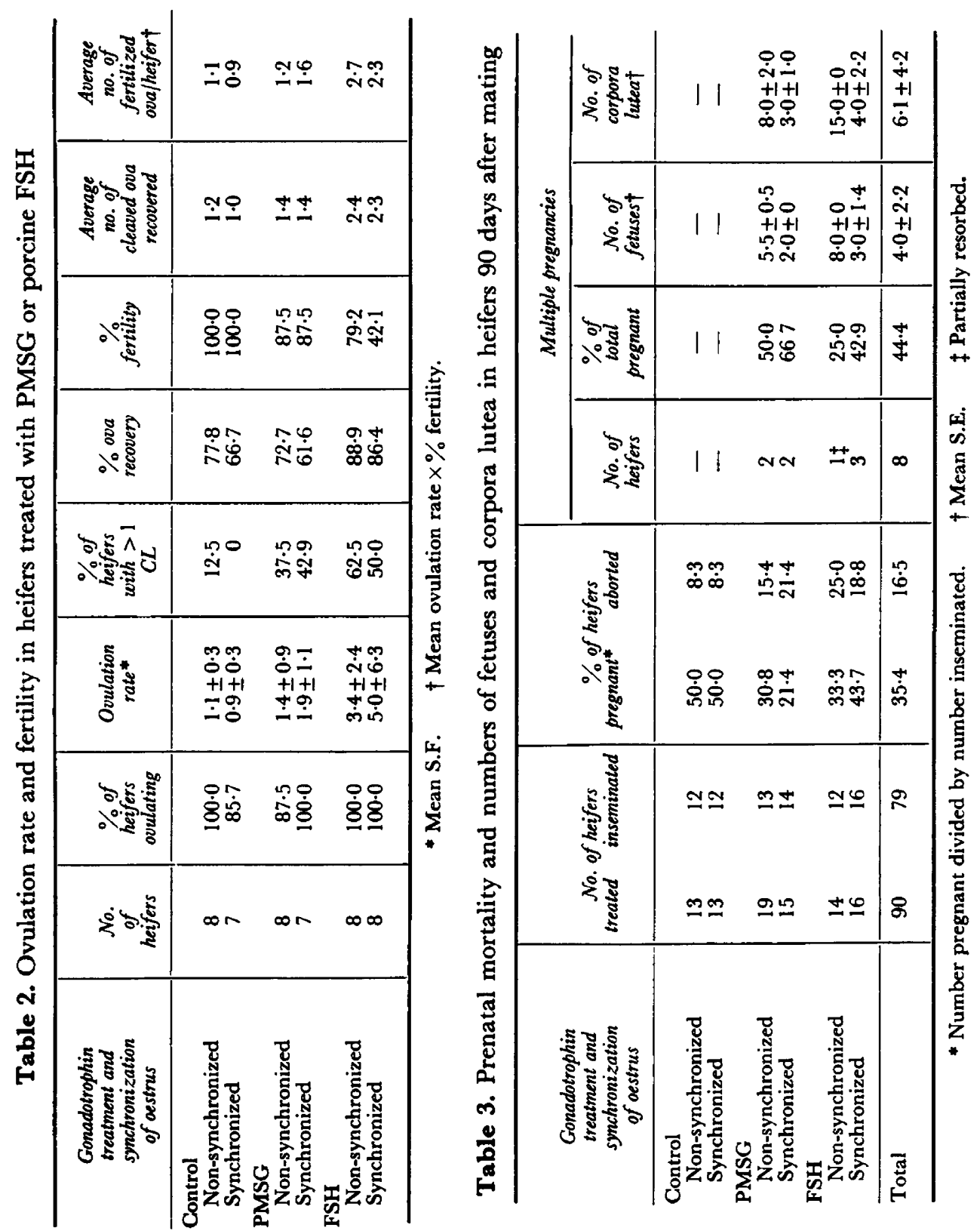


heifer with two corpora lutea. This animal had been treated with FSH during the normal oestrous cycle.

Abortions had occurred in a high percentage of the heifers by approximately 90 days after insemination (Table 3 ). There were no apparent differences in prenatal mortality during the first trimester of gestation between the PMSGand FSH-treated animals $(21.4$ and $18.8 \%$, respectively). Prenatal losses were higher in the PMSG and FSH groups than in the controls. It was observed at necropsy that two of the control heifers had aborted.

The pregnancy rate was slightly higher in heifers treated with FSH than in those treated with PMSG, but the percentage of pregnancies that were multiple pregnancies was higher in the PMSG-treated group (Table 3). In the heifers found to be pregnant at necropsy, average ovulation rates were higher than the average number of fetuses $(6 \cdot 1 \pm 4 \cdot 2$ and $4 \cdot 0 \pm 2 \cdot 2$, respectively). Two heifers with single pregnancies had more than one corpus luteum and more than one corpus luteum were also present in five of the heifers classified as having aborted.

In the treated heifers with two or three corpora lutea, $75 \%$ occurred in only one ovary. In all heifers with more than one corpus luteum, $53 \%$ occurred in only one ovary. Of the eight heifers with more than one fetus at the time of necropsy, $75 \%$ had corpora lutea in joth ovaries but $50 \%$ of the multiple pregnancies were contained in one uterine horn.

The interval from the last gonadotrophin injection to oestrus was not affected by the species source of the gonadotrophin, but was affected by progestagen treatment. In the heifers given PMSG or FSH during the normal oestrous cycle, $80 \%$ were observed to be in oestrus within a 3-day period (Days 2 to 4 ) after the last gonadotrophin injection. In those injected with PMSG or FSH during progestagen feeding, $58 \%$ were observed to be in oestrus within a 3-day period after gonadotrophin treatment.

\section{DISCUSSION}

It has been shown that the PMSG-treatment regimen used in this study will successfully induce limited multiple ovulation in the bovine when given during the normal oestrous cycle (Schilling \& Holm, 1963; Laster et al., 1971). The similarity between the ovulation rate in this study and the rates reported by Gordon et al. (1962), Schilling \& Holm (1963) and Laster et al. (1971) indicate that an injection of an LH source after the PMSG injections is not necessary for the successful induction of limited multiple ovulation.

The FSH-injection regimen used was similar to that reported by Bellows et al. (1969). There are few reports on the ovulation rate of cattle treated with levels of FSH expressed in terms of a standard unit. From the results of Bellows \& Short (1971), it would appear that a dosage between $7 \cdot 6$ and $15.2 \mathrm{mg} \mathrm{FSH}$ (NIH-FSH-S1 equiv.) would give the most desirable ovulation rate for inducing multiple pregnancies.

The results of this study do not support the findings of Dzuik, Donker, Nichols \& Peterson (1958) and Bellows \& Short (1971) that purified extracts of FSH result in more satisfactory and predictable results than those obtained 
with PMSG. The conclusion reached may depend on the biological potency rather than the species source of the gonadotrophin. In this study, the ovulation rates induced by the PMSG treatment were more desirable and less variable than those obtained with FSH. It has been shown, however, that porcine FSH, given twice daily for 5 days, can result in a high percentage of animals with two corpora lutea (Bellows et al., 1969).

The average number of fertilized ova/animal increased with increased ovulation rates. In the FSH-treated animals, the ovulation rate was higher and the fertilization rate was lower than desirable for obtaining a high percentage of twin pregnancies, which appear to be the most desirable form of multiple births in cattle (Gordon et al., 1962; Turman et al., 1971). The lower fertilization rate with the FSH compared with the PMSG treatment is probably due to the difference in ovulation rate and associated phenomena rather than to the species source of the gonadotrophin. The percentage of ova recovered was not affected by ovulation rate or progestagen treatment. Bellows et al. (1969) found that synchronization of oestrus and FSH treatment decreased the recovery of ova.

Abortions have been observed in cows and heifers with multiple pregnancies and the incidence of prenatal mortality appears to be higher in heifers than in cows (Gordon et al., 1962; Laster et al., 1971). The specific causes of prenatal mortality in animals with induced multiple ovulations have not been established because, in most studies in which prenatal losses were observed, the maintenance of the pregnancies may have been altered by attempts to study ovarian activity or to determine the number of fetuses. The estimated number of fertilized ova/heifer was higher in the FSH- than in the PMSG-treated groups, but the rates of prenatal mortality were similar (Table 3 ). This suggests that prenatal mortality was not highly associated with the number of fetuses. The reason for the abortions in the two controls is not known.

The number of heifers with multiple ovulations from only one ovary and the number with multiple pregnancies in a single uterine horn may have been partially responsible for the high percentage of prenatal losses. Rowson, Lawson \& Moor (1971) reported higher prenatal losses in unilateral than in bilateral twin pregnancies.

A review of the literature on variation in ovarian response among different experiments and the results of this study demonstrate the necessity of expressing the biological potency of gonadotrophin preparations used to study doseresponse relationships on a standard international equivalent basis and perhaps a need to assay the biological potency of the preparation near the time of usage. It appears that the PMSG-treatment regimen used in this study will result in limited multiple ovulation and satisfactory fertility, but higher than desirable ovulation rates are elicited with $12 \mathrm{mg}$ porcine FSH (NIH-FSH-S1 equiv.) administered in ten equal doses.

\section{AGKNOWLEDGMENTS}

Appreciation is expressed to Dr J. B. Jewell, Ayerst and Co., New York, for the gift of PMSG (Equinex); Dr William Brown, Syntex Corp., Palo Alto, California, for the gift of CAP; Dr J. D. Fisher, Armour Pharmaceutical Co., 
Kankakee, Illinois, for the porcine FSH (Lot No. K498159), which was a gift to Dr R. M. Melampy; Dr R. M. Melampy and Dr L. L. Anderson, Iowa State University, Ames, for bioassay of the porcine FSH; and the Nebraska Agricultural Experiment Station, University of Nebraska, Lincoln.

\section{REFERENCES}

Bellows, R. A., Anderson, D. C. \& Short, R. E. (1969) Dose-response relationships in synchronized beef heifers treated with follicle stimulating hormone. J. Anim. Sci. 28, 638.

Bellows, R. A. \& Short, R. E. (1971) Superovulation and multiple births in beef cattle. F. Anim. Sci. 34, Suppl. 1, 67.

Dzuik, P. J., Donker, J. D., Nichols, J. R. \& Peterson, W. E. (1958) Problems associated with the transfer of ova between cattle. Anim. Breed. Abstr. 27, 747.

Gordon, I., Williams, G. \& Edwards, J. (1962) The use of serum gonadotrophin (PMS) in the induction of twin-pregnancy in the cow. 7. agric. Sci., Camb. 59, 143.

Hafez, E. S. E. (1962) Physiology of mammalian ova. In: Reproduction in Farm Animals. Ed. E. S. E. Hafez. Lea \& Febiger, Philadelphia.

LASTER, D. B. (1972) Follicular development in heifers infused with follicle-stimulating hormone. J. Reprod. Fert. 28, 285.

Laster, D. B., Turman, E. J., Stephens, D. F. \& Renbarger, R. E. (1971) Ovulation rates of beef cows and heifers treated with equine gonadotropin (PMS) and chorionic gonadotropin (HCG). 7. Anim. Sci. 33, 443.

Rowson, L. E. A., Lawson, R. A. S. \& Moor, R. M. (1971) Production of twins in cattle by egg transfer. J. Reprod. Fert. 25, 261.

Schilling, E. \& Holm, W. (1963) Investigation on induction of limited multiple ovulations in cattle. 7. Reprod. Fert. 5, 283.

Steel, R. G. D. \& Torrie, J. H. (1960) Principles and procedures of statistics. McGraw-Hill, New York.

Steelman, S. L. \& Pohley, F. M. (1953) Assay of the follicle stimulating hormone based on the augmentation with human chorionic gonadotropin. Endocrinology, 53, 604.

Turman, E. J., Laster, D. B., Renbarger, R. E. \& Stephens, D. F. (1971) Multiple births in beef cows treated with equine gonadotropin (PMS) and chorionic gonadotropin (HCG). J. Anim. Sci. 32, 962.

Vincent, C. K. \& Mills, A. G. (1972) Gonadotropin levels for multiple births in beef cattle. J. Anim. Sci. 34, 77.

WINER, B. J. (1962) Statistical principles in experimental design. McGraw-Hill, New York. 